\title{
The Discussion about International Agricultural Logistics and Distribution System of Henan Wanbang
}

\author{
Shumin Luo ${ }^{1}$ and Hua Xuan ${ }^{1}$ \\ ${ }^{1}$ Management Engineering Department, ZhengZhou University, ZhengZhou, China
}

\begin{abstract}
With the development of economic globalization, The current development of China's agriculture has shifted from production areas to circulation areas, People on fresh produce a concern degree higher and higher, the key is to ensure agricultural products fresh degree is the logistic distribution. This article takes the distribution system He nan wan bang International Agricultural Logistics Park for the study, From the current situation, agricultural logistics perspective, Through Wan bang distribution status, Problems distribution system was investigated, Also it includes its logistics strategy, organizational design and distribution, distribution function, operations and process design, information systems and mechanical equipment analysis, business performance evaluation and so on. With related theory, To study the issue of logistics through knowledge learned, Put forward reasonable solutions, Wan bang optimized logistics and distribution system of agricultural products.
\end{abstract}

\section{Introduction}

From the point of the current situation in our country, lack of competitiveness of agricultural products, not only on the quality and appearance but also can be seen in terms of the transaction cost, loss, waste. To seek a more reasonable scientific agricultural products logistics distribution system, to promote the farmers' income, distribution of the improvement of service quality, reduce distribution costs, to solve the agricultural product circulation speed,there are great significance. In the rapid development of zhengzhou economy, the logistics industry of agricultural products will play an important support role for its development, agricultural products logistics industry is becoming more and more important, so the study of Chinese agricultural products logistics is imperative [1-3]. Among all nations based on the investigation and study of distribution system, starting from the distribution system of all the nations, and analyses its general situation, the analysis of the agricultural products logistics distribution system, existing problems.

\section{Logistics distribution system analysis}

\subsection{Distribution of the organizational design and distribution functions}

The operation of the Wanbang logistics distribution system are mainly composed of self-run logistics distribution, private home car transport is complementary. Of self-run logistics for all future in Henan, the main transportation forces are buying their cars. Information network and logistics management software which is called the logistics information system, its composition including people, processes and equipment, can provide the information for some functions 
including logistics managers perform the planning and implementation of control, it is not exist independently but part of the enterprise information system, is not only a subsystem of logistics system, is also a kind of interaction system [4]. Among all the distribution of organizational design including its logistics distribution center organization chart and personnel and job responsibilities. Distribution center structure diagram as shown in figure 1:

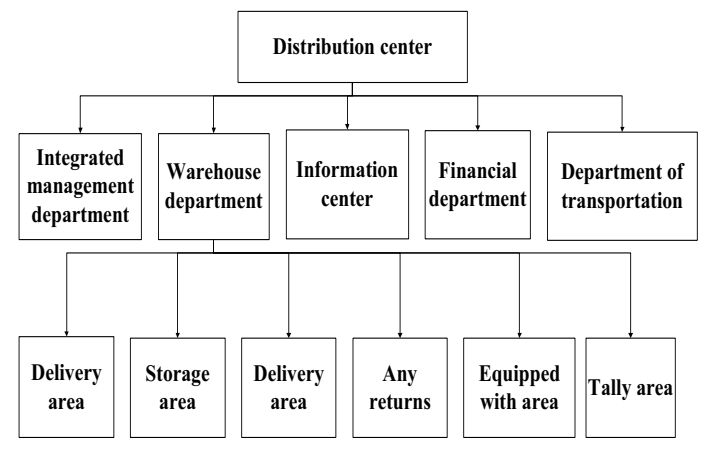

Fig. 1. Distribution center structure.

Distribution system, its distribution function mainly has several aspects: (1)Stock goods. From the aspects of distribution, the role is preparation and collection of the goods, goods ordering, goods collection, purchasing goods and its interrelated settlement, such as quality inspection, etc. When costs are very high, in the very great degree will reduce distribution efficiency. Agricultural products, distribution center.(2)storage. The two forms of storage : store for future use and temporary storage. temporary storage is to distribution in the specific date, according to the provisions of sorting and distribution, do less work for mass storage on the reasonable freight yard. Because the whole storage efficiency is determined by the whole storage quantity, therefore, the portion of the temporary number will not influence the overall benefits of store, only cause certain influence to whether convenient work, so do not strict control the number of temporary storage. And the storage of Wanbang logistics configuration is mainly the temporary storage, this is according to its own cold storage of fresh and frozen goods storage depots and other facilities. (3)sorting and distribution. At the time of delivery the mutual competition between different distribution enterprises, and to improve their own economic benefits, sorting and distribution is an extension that must be carried out [5]. Sorting, distribution is one of the key elements for a distribution system level. sorting and distribution of Wanbang logistics mainly depends on manual work, its modernization level is not high. (4)Assembling. How to make the goods that the different users need to delivery together,for better use of resources through collocation, loading, this needs assembling; This can effectively reduce the delivery cost, to a large extent improve the level of service delivery. But Wanbang in many cases cannot achieve the payload of the vehicle. (5)Distribution transports.it is the regional transportation and the last transportation, its transportation facility are cars. Compared with the main transport has the following characteristics: short distance, small size, high cost. And it has a route selection problem. Due to the complexity of city traffic route condition, the big number of users, the characteristics of distribution transport: how to choose the best, let assemble and route fit effectively [6].

\subsection{The process of logistics distribution center}

The operations of Wanbang logistics distribution center include: Warehouse operation, Tally work, the customer and order management, EX-warehouse operation, Loading and unloading and handling, distribution operation. The process design as shown in figure 2: 


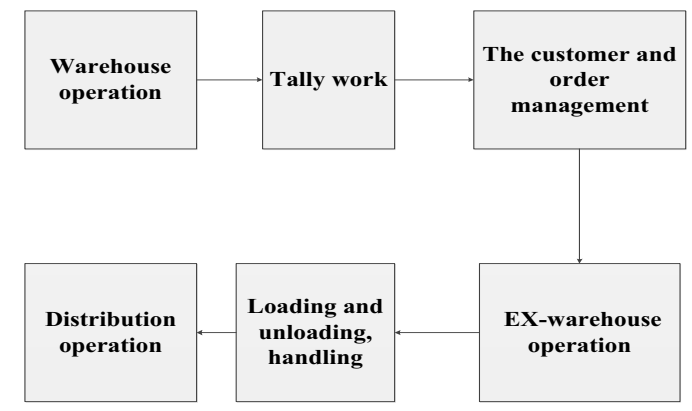

Fig. 2. Wangbang logistics distribution center process design.

\section{SWOT analysis}

Due to Wangbang logistics distribution system operation is a self-run logistics distribution, and their private car to do auxiliary work. SWOT analysis of this model of Wangbang: Superiority (S), weaknesses (W), opportunities (O), threats $(\mathrm{T})$.such as follows:

(1)Superiority (S): save money, keep strong competitiveness and make four logistics(Macro and micro logistics and social logistics and logistics, international logistics and regional logistics, general logistics and special logistics)seems more tightly, because control agricultural products logistics, so as to improve the efficiency of the logistics operation, reduce capital takes up, save the expenses [7]. Its surrounding comprehensive traffic has formed the transportation network, has developed the highway transportation system and railway transportation system. the development of Wangbang with thick solid foundation. The highway of Zhengzhou to Minquan ,it is surrounded by a avenue, Kowloon, Hong Kong and Macao and neighboring Beijing highway, highway three thousand, north longhai railway lines [8].

(2)Weak (W):Because Wangbang 's distribution system increases the burden on its investment, making it less capable of resisting market risk. Because the initial investment is too large, the logistics of its own building has not yet reached a more appropriate level in the system management requirements, in the professional aspects of the high enough, difficult to manage and so on [9]. And because of the relatively inactive geographical location, the lack of professional agricultural logistics management personnel, logistics management personnel but also efforts, the private car market led to a certain degree of confusion.

(3)Opportunity (O): Adjacent to the Zhengzhou International Logistics Park under construction, the traffic advantage is being greatly strengthened, laying a solid foundation for its future expansion and development. The government attaches great importance to the logistics of agricultural products, the Ministry of Commerce, Henan Province, city and county leaders at all levels with the strong support of Henan Wanbang to accelerate the development of the central region has become the most influential large-scale distribution center at the national level, Key Functions of Agricultural Products Logistics Hub. With a large self-built, including vegetables, fruit trading area, cold storage facilities, and its strong competitiveness, will be the Central Plains region's largest agricultural products market [10].

(4)Threat $(\mathrm{T})$ : the market demand of modern agricultural products logistics service is insufficient, because there is contradiction between supply and demand, leading to supply greater than demand and short supply. Because the more accurate the information of supply and demand is relatively difficult, so make the agricultural products logistics links exist bigger risks. Because of China's entry into the WTO, foreign logistics enterprises also have threat to Wanbang logistics. Agricultural products logistics has a relatively high risk at the same time, because it is easy to corrupt, follow the seasonal change characteristics of agricultural products is "fresh" meaning and life place, but the short date of agricultural products with good quality and very easy to corrupt, and other characteristics, to a great extent, restricts the transport path as well as the trading time, so the preservation condition of circulation and the transport efficiency proposed higher specification, and customers need to improve the logistics service requirements, the need to work hard for future logistics. 


\section{4 comparative analysis with foreign}

\section{1 present situation of development and characteristics of the major foreign countries}

The early country of the agricultural products logistics research is the United States, then other countries also gradually began to study. Logistics is towards the direction of further development in the 1980, the logistics theory gradually became mature. foreign logistics development of agricultural products, mainly has the following three models:

(1)Japan, South Korea, as the important representative of east Asian model.

They are in the wholesale market as the main channel, the buying and selling as an important means. Have the perfect logistics infrastructure, which included in the distribution center of packaging and processing facilities, warehouse at low temperature and normal temperature, but also engaged in the distribution of electronic commerce, form a complete set, ready to goods, etc. They supply of agricultural products logistics distribution has the following several characteristics: (1)the links in the circulation channels, cost is high; Its supply process is "product-wholesalemiddle wholesale- retail - consumption" (2)through (1)the flow of process, it can be seen that the uneven distribution of profits; (3)although the uneven distribution of profits, but the circulation work standardization, the legal system more strengthen, speed and efficiency are high.

(2)France, the Netherlands and other countries as the main representative of the western European model.

Western mode of wholesale market circulation ratio relatively smaller than east Asian model, and a lot of wholesale market still adhere to this principle the public welfare, it is compared with the east Asian model. Mainly through the network to form agricultural products supply chain, including suppliers, manufacturers, wholesalers, retailers, and to the very many country in the world of consumer people to provide services through electronic trading of agricultural products. And they're in refrigeration industry development is very positive, has highly efficient cooling and freezing technology equipment.

The main characteristic of Western Europe pattern is : (1)To encourage the prenatal and postnatal related enterprises built in the countryside, and the production, processing and marketing in one level. (2)Built wholesale market about agricultural products, its nature is public welfare, it is relatively perfect, contemporary; (3)A relatively standardized product and manufacture of agricultural products.

(1)United States, Canada, and Australia is the main representative of the pattern of North America.

Direct marketing system development is better, and the main mode of agricultural products sales and direct sales. Information based development of agriculture is very good, they built information management system for their entire national crop variety resources, provide services to the entire country experts.

These countries agricultural products logistics distribution mainly has the following characteristics: (1)The origin and market are relatively concentrated. (2)Sales site are larger cities, wholesale market is located in big cities. (3)Circulation channels is shorter, less in the middle of the process, high efficiency.

\subsection{Draw lessons from foreign agricultural products logistics mode}

Three modes of foreign countries in the development of the agricultural products logistics is good with the government's macroeconomic regulation and control. Because the of government to promote the development of agricultural products logistics is very important. Government should also play a good role in macroeconomic control of the agricultural products logistics, it can from the following several aspects: formulate relevant laws and regulations to regulate some bad phenomena in China logistics market of agricultural products, slowly to control and improve the current non-standard phase at the present stage; Insist on open to other countries, to learn the modes and experience of the three countries, and make the necessary cooperation in the logistics of agricultural products; Our country can learn from the three modes, advanced agricultural logistics technology to our country, make our country more modern in the agricultural products logistics. Based on Wangbang analysis of the logistics system, which draw lessons from the above 
experience of foreign research, to improve its distribution facilities and establish a modern distribution center of logistics, it is a valuable asset for it.

\section{The problems and solutions}

\subsection{Analysis on the Problem of Logistics Distribution System of Wanbang and the solutions}

The Problem of Logistics Distribution System of Wanbang are as follows:(1)its own logistics and distribution system is not perfect(2)lack of professional logistics personnel, technology and facilities support(3)The coordination mechanism of departments, regulations and market access is not perfect.

The Solutions to the Problem of Wanbang 's Existence are as follows:

\subsubsection{Establish and improve the sector, market access, regulatory aspects of the coordination mechanism}

For the sector, regulations, market access and other aspects of the coordination mechanism is not perfect, Wanbang market sector should develop the market of modern agricultural logistics laws and regulations to unify the standards of the market, regulate market behavior on agricultural logistics, the establishment of quality standards and industry norms Agricultural products logistics services, but also the corresponding policy development, agricultural flow regulations, strengthen the management of the market, regulate some of the behavior of the market competition. Crack down on bad business bad behavior, but also a healthy and orderly market.

\subsubsection{Professional agricultural products logistics distribution center establishment}

In the distribution system for the production and sales from the role of communication and distribution logistics distribution center, which has the following characteristics: (1)fast response. On the upstream logistics and downstream logistics and distribution needs, it is faster and faster response. (2)functional integration. Just like integration between each channel of the logistics, for example in the logistics and other parts of the supply chain integration. (3)standardization of distribution operations. Improve the efficiency of logistics operations and its benefits, based on the operation of the logistics and distribution processes, so that relatively more complex operations tend to simplify (4)series of distribution services. In addition to door-to-door, you can expand the logistics of the following aspects: distribution consulting, inventory control, payment recovery. (5)distribution means modernization. If you want a larger scale, logistics and distribution technology, logistics equipment and management needs to be more modern, which can be through the use of advanced logistics technology, logistics equipment and management, logistics and distribution are the main support. (6)distribution organization network. Including logistics nodes, distribution centers and other network facilities, mainly refers to the logistics and distribution network system is complete and sound. (7)logistics and distribution management legalization. We must have sound laws and regulations and act according to law, according to the chapter, regardless of macro or micro.

And it has the following functions:(1)in the logistics cost control. (2)to achieve intensive inventory. (3)It is conducive to the realization of commercial separation. (4)It is conducive to grasp the sales information. (5)can promote product sales, improve customer service levels.

Through the above characteristics and role of logistics distribution center, and then for the Henan Wanbang on the status of agricultural logistics, as well as Wanbang Future Logistics development, the establishment of agricultural logistics and distribution center is a good choice. When a complete distribution center is established, the optimization of the transportation route can be solved by solving the shortest path problem according to the solution of operations research. 


\subsection{3 strengthen the logistics personnel training efforts ,take new logistics technology, improve the utilization of facilities}

Henan Wanbang can set up their own logistics personnel training institutions, their staff on a regular basis to other logistics companies to visit and learn to understand their positions in the company's entire system, learn modern information technology. In addition, with the pay and benefits to retain logistics personnel, let them play a greater role for the company.

Wanbang logistics vehicles, while equipped with GPS, bar code technology, EDI electronic data exchange and RF radio technology, but compared with other logistics companies still have a certain gap. In order to make its logistics and distribution system more better, cost more less, this technology is to be greatly improved.

Although Wangbang has its own cold storage, forklifts, warehouses and other equipment, but the utilization rate is very small, which can use "puerile" this idea, leased them to customers in need, rented them to the business park, not only Improve its utilization, but also reduce the waste of agricultural products.

\section{Conclusion}

With the development of economic globalization, the agricultural logistics industry will play an important supporting role in the economic development of our country on the basis of China's national conditions. The paper structure is clear, starting from the agricultural product logistics distribution system, Through the analysis of the general situation of enterprises, the problems of logistics and distribution of agricultural products, as well as the comparison of the same industry abroad, And through the knowledge learned by the author, put forward some suggestion to solve their problems, and also concluded that logistics and distribution system is very important for the development of logistics, It is an important factor for its success.

\section{References}

1. Liu Chunyan, Pan Feng.Study on the Logistics Distribution System of Fresh Agricultural Products under the Condition of Intelligent Logistics.Chinese Market, 10, (2013).

2. LUO Xuqin, TONG Xiaohu, YU Jun.Study on the Agricultural Products Logistics Distribution System Based on E-commerce. Electronic Commerce, 1, (2014).

3. Zhang Xue. Qingdao modern logistics and distribution system of agricultural products. Ocean University of China master's degree thesis printed version. 6, (2011).

4. Li Qing, Liu Binglu. JIT-based way of aquatic products cold chain logistics and distribution .Goods and quality of scientific theory . 2, (2011).

5. Liu Yangqing. Current situation of the development of Fresh agricultural product distribution model in E-commerce environment .Logistics engineering and management, 2, (2014).

6. Zhang Na. Liu Jian. Fresh agricultural products "last mile" distribution of Mianyang City.Trade, 21,(2014).

7. Liu Xudong. Analysis of JIT distribution model of aquatic products based on SWOT analysis. Logistics Engineering and Management, 6, (2012).

8. Xing Jiangbo. Fresh agricultural products logistics distribution network optimization of E-commerce environment. Dissertation,9,(2012).

9. GAO Xuedong, GU Shujuan, BAI Chen, WU Sen. Clustering Algorithm Considering the Structure of Logistics Distribution Network and Delivery Quantity Constraints.Systems Engineering Theory and Practice 1, (2012).

10. Wang Junjiao. Aquatic product distribution model optimization analysis of Dalian area. Shopping Center .22,(2014). 